\title{
X-RAY DIFFRAGTION TOPOGRAPHIC OBSERVATIONS OF THE LARGE-ANGLE GRAIN BOUNDARY IN ICE UNDER DEFORMATION
}

\author{
By T. HondoH and A. Higashi \\ (Department of Applied Physics, Faculty of Engineering, Hokkaido University, Sapporo, \\ Japan o6o)
}

\begin{abstract}
Abstracr. Large-angle tilt grain boundaries in artificially-grown ice bicrystals were observed by the method of X-ray diffraction topography. In bicrystals for which misorientation angles satisfy the conditions of a high-density coincidence site lattice (CSL) at the boundary, the images of fine parallel line defects appear on the topograph taken immediately after a light deformation. Since these images disappear in a time period between several hours and a few days and reappear again at the same sites when the specimen is deformed subsequently, it is concluded that these line defects are not stable like the boundary dislocations but may be steps generated on the boundary to form facets which coincide with the high-density CSL plane. X-ray topographic images of boundaries which do not satisfy the conditions of a high density CSL are complex and difficult to interpret, although some of the images indicate that there may be different types of structures on such boundaries.
\end{abstract}

RÉsumÉ. Observations par topographie $X$ des joints de grains a forte désorientation dans la glace en cours de déformation. On étudie les joints de grains à forte désorientation dans des bicristaux de glace artificielle par topographie $\mathrm{X}$. Pour les bicristaux dont la désorientation angulaire satisfait le condition de grande densité CSL (réseau de coïncidence), juste après une faible déformation, on observe des défauts sous forme de fines lignes parallèles. Ces lignes disparaissent dans un laps de temps compris entre quelques heures et plusieurs jours, puis elles réapparaissent aux mêmes endroits lorsque l'échantillon est redéformé. On peut donc en conclure que ces défauts ne sont pas stables comme des discontinuités des joints de grains, mais pourraient être des marches créées sur le joint pour former des facettes correspondant à une forte coïncidence. Les topographies des joints de grains qui ne satisfont pas les conditions de forte coincidence sont complexes et difficiles à interpréter. Cependant, quelques unes d'entre elles montrent qu'il pourrait y avoir plusieurs sortes de structure dans ces joints.

Zusammenfassung. Röntgentopographische Beobachtungen der Grosswinkelkorngrenze in Eis unter Verformung. Grosswinkelkippkorngrenzen in gezüchteten Eis-Zweikristallen wurden mit Hilfe von Röntgenbeugungstopographie beobachtet. In Zweikristallen, deren Fehlorientierungswinkel an der Grenzfläche die Bedingung für ein Koinzidenzstellengitter (CSL) hoher Dichte erfüllt, erscheinen auf der Topographie, die unmittelbar nach einer leichten Verformung aufgenommen wurde, Bilder feiner paralleler Linienfehlstellen. Da diese Bilder im Zeitraum einiger Stunden bis weniger Tage verschwinden und nach darauf folgender Verformung der Probe an den gleichen Stellen wieder auftreten, wird geschlossen, dass diese Linienfehlstellen nicht stabil sind wie Korngrenzenversetzungen, sondern Stufen sein können, die auf der Grenzfläche gebildet wurden und die sie mit Facetten versehen, welche mit der Ebene des Koinzidenzstellengitters hoher Dichte zusammenfallen. Röntgentopographische Aufnahmen einer Korngrenze, welche die Bedingung der Koinzidenzstellengitters nicht erfüllt, sind schwierig zu deuten. Dennoch zeigen einige von ihnen an, dass es auf derartigen Korngrenzen einige verschiedene Strukturtypen geben mag.

\section{INTRODUCTION}

In spite of the important role which the grain boundary plays in the deformation of polycrystalline ice, no microscopic study has ever been carried out into the structure and behaviour of large-angle grain boundaries in ice. The present study is an attempt to make clear the microscopic processes which occur during deformation at large-angle boundaries, using the method of X-ray diffraction topography.

Recently, it was confirmed by electron and field-ion microscopy that some ordered structures exist even in the large-angle grain boundaries of metals at certain special misorientation relationships (see, for example, Loberg and Norden, 1976). Grain-boundary dislocations on such ordered boundaries were also observed. However, X-ray diffraction topography has not been used so far for observations of grain-boundary structures. X-ray topography has advantages over electron microscopy in that it is sensitive to small strain fields, and large specimens can be scanned, although the resolution is low. In order to have good images on an X-ray topograph, it is necessary for the crystal specimens to have low 
dislocation densities; it is this requirement which might have prevented the observation of grain boundaries by X-ray topography. Since ice is comparatively transparent to X-rays and a technique for growing bicrystals of ice with a low dislocation density has been developed in our laboratory, X-ray diffraction topography has become a good method by which to observe grain boundaries in ice.

Grain boundaries of some bicrystals were observed by X-ray diffraction topography in the as-grown state and after successive deformations. Differences between images and the behaviour of images with deformation and subsequent annealing are discussed in terms of the coincidence-site lattice concept (CSL). Two kinds of bicrystal were grown, with tilt grain boundaries having $c$-axis misorientations around the $\langle\mathbf{I O} \overline{\mathrm{I}} \mathrm{O}\rangle$ rotation axis of $34^{\circ}$ and $47^{\circ}$. The $34^{\circ}$ boundary is expected to have an ordered structure in CSL and the $47^{\circ}$ boundary is not.

\section{Experimental procedure}

Since grain-boundary defects, in general, cause only small strain fields, it is difficult to distinguish their images from those of lattice dislocations if dislocation densities are high in the grains on both sides of the boundary. Therefore, it is necessary to use bicrystals with low dislocation densities for studies of grain-boundary structures. It is also necessary to have a fixed misorientation relation in the bicrystals together with a very flat grain-boundary plane. Although it was not an easy task to obtain good bicrystals, experiments in our laboratory have made it possible.

Ice bicrystals which had $\langle\mathbf{I O} \overline{\mathrm{I}} \mathrm{O}\rangle$ tilt large-angle grain boundaries were grown parallel to the $\langle$ IO $\overline{\mathrm{I} O}\rangle$ axis by the Czochralski method. A seed bicrystal was made by growing two single crystals of low dislocation density in such a way that the $c$-axes rotated $\theta$ around the $\langle\mathbf{I} \overline{\mathrm{I}} \mathrm{O}\rangle$ axis. When the growth direction was normal to the rotation axis $\omega$, the grain-boundary plane tended to curve strongly and many small-angle grain boundaries were emitted from it. On the other hand, when the growth direction was parallel to $\omega$, the boundary extended as a plane in the direction of growth. It grew almost exactly parallel to the direction of $\omega$ but sometimes bent slightly in the direction normal to $\omega$ and a few small-angle grain boundaries were emitted from the curve of the boundary. Good portions cut from a bicrystal grown parallel to $\omega$ were used for seeds as well as for the experiments. Good bicrystals were obtained in which the dislocation densities were between $10^{6} \mathrm{~m}^{-2}$ and $10^{8} \mathrm{~m}^{-2}$.

The rotation angle $\theta$ was fixed at approximately $34^{\circ}$ (CSL) or $47^{\circ}$ (not CSL). The grainboundary plane should coincide with the ( $\overline{\mathrm{I}} 2 \overline{\mathrm{I}} \mathrm{I})$ plane in the case of $\theta=34^{\circ}$, but for $\theta=47^{\circ}$ the grain boundary does not coincide with any plane of low indices if the boundary plane bisects the rotation angle.

Specimens used in this work were cut and formed by band sawing and planing but without chemical polishing. Dislocations, which are generated at the surface due to the mechanical stress which accompanies such preparation methods, disappeared after ageing for a few days and did not affect the observations.

All observations and deformations were carried out in a cold room at $-20^{\circ} \mathrm{C}$. X-ray diffraction topographs were taken using a large Lang camera (scanning area $8 \times 10 \mathrm{~cm}^{2}$ ) with a powerful rotating $\mathrm{X}$-ray source (Mo target) operated at $50 \mathrm{kV}$ and $90 \mathrm{~mA}$. Generally, a pair of topographs was taken having the same diffracting plane for both crystal grains in order to observe both sides of the boundary.

Bicrystal specimens, with a scanned area of several square centimetres and a thickness of several millimetres (as illustrated in Figures I, 2, and 4) were subjected to small uniaxial compressive strains. Applied stresses are given in the figure captions together with the duration of deformation. 


\section{Results}

\section{I. Specimens with $\theta=34^{\circ}$}

The pair of topographs shown in Figure I (a) was taken with a [Iōo] g-vector for both grains. The grain-boundary plane ABCD can be clearly identified by the Pendellösung fringes, and very few dislocation images can be seen in both grains. After a light deformation with shear stress of about $2.3 \times 10^{5} \mathrm{~Pa}\left(2.4 \mathrm{~kg} / \mathrm{cm}^{2}\right)$ acting on the grain boundary for about $10 \mathrm{~s}$, many fine lines (parallel to $\mathbf{I}-\mathbf{I}^{\prime}$ as shown in Figure $\mathbf{I}(\mathrm{b})$ ) appeared on the boundary plane in
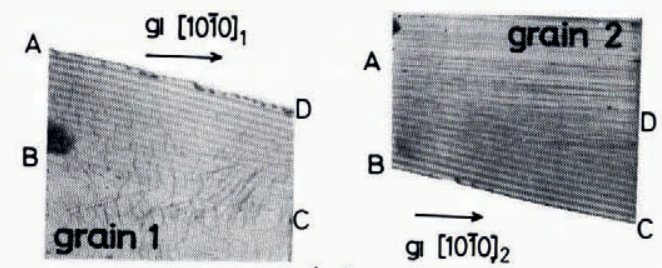

(a)
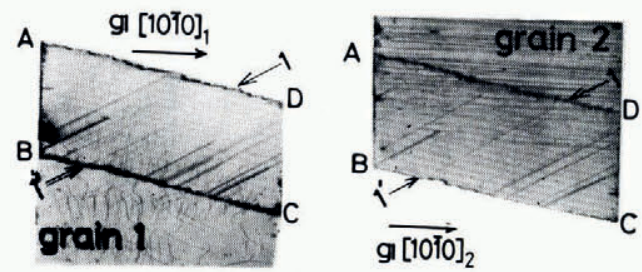

(b)

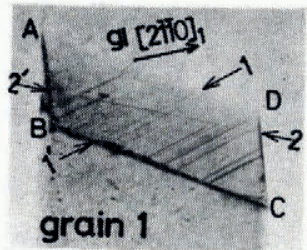

(c)

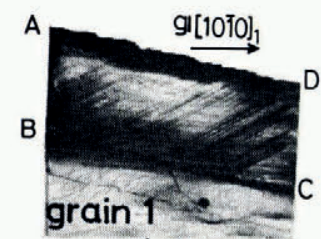

(d)

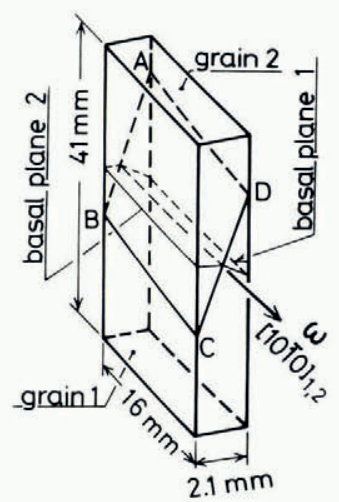

(e)

Fig. I. Line defects on a $[\mathrm{IO} \overline{\mathrm{I}} \mathrm{O}] / 34^{\circ}$ tilt grain boundary.

(a) A pair of $X$-ray diffraction topographs taken with $[\mathbf{I O} \bar{I} O] \mathbf{g}$-vector of both grains before the specimen was deformed.

(b) Topographs of the specimen just after the first light deformation. Note parallel line images $I-I^{\prime}$. (c) Topographs taken with $(2 \bar{I} \bar{I} O)$ diffracting plane of the specimen just after the second light deformation. Note parallel line
images $2-2^{\prime}$.

(d) Topographs of the specimen aged for $2 \mathrm{~d}$ after a deformation for a long period: shear stress of $9.8 \times 10^{4} \mathrm{~Pa}\left(\mathrm{I} \mathrm{kg} / \mathrm{cm}^{2}\right)$ on the boundary for $I h$.

(e) Schematic illustration of the specimen. 
topographs taken with the same diffraction conditions as those in Figure I (a). Since these parallel line images are recognized in both topographs of grains $\mathrm{I}$ and 2 , it is clear that these images originated from strain fields around grain-boundary defects generated by deformation. Most of them extended from one end of the boundary plane to the other, but some of them terminated in the middle of the boundary plane. These images disappeared within a few hours, during ageing at $-20^{\circ} \mathrm{C}$, so it is difficult to obtain topographs of these defects taken with various diffraction conditions to determine the Burgers vector.

When this specimen was subjected to subsequent deformation, almost the same images again appeared on the topographs. Figure $\mathrm{I}(\mathrm{c})$ shows a topograph taken with a [2 $\mathrm{i}$ io] g-vector immediately after the second deformation. We can observe another type of parallel line defect (designated $2-2^{\prime}$ ) on this topograph in addition to those of Figure $\mathrm{I}(\mathrm{b})$. The crystallography of this specimen is shown in Figure $\mathrm{I}(\mathrm{e})$. The rotation axes $\omega$, determined
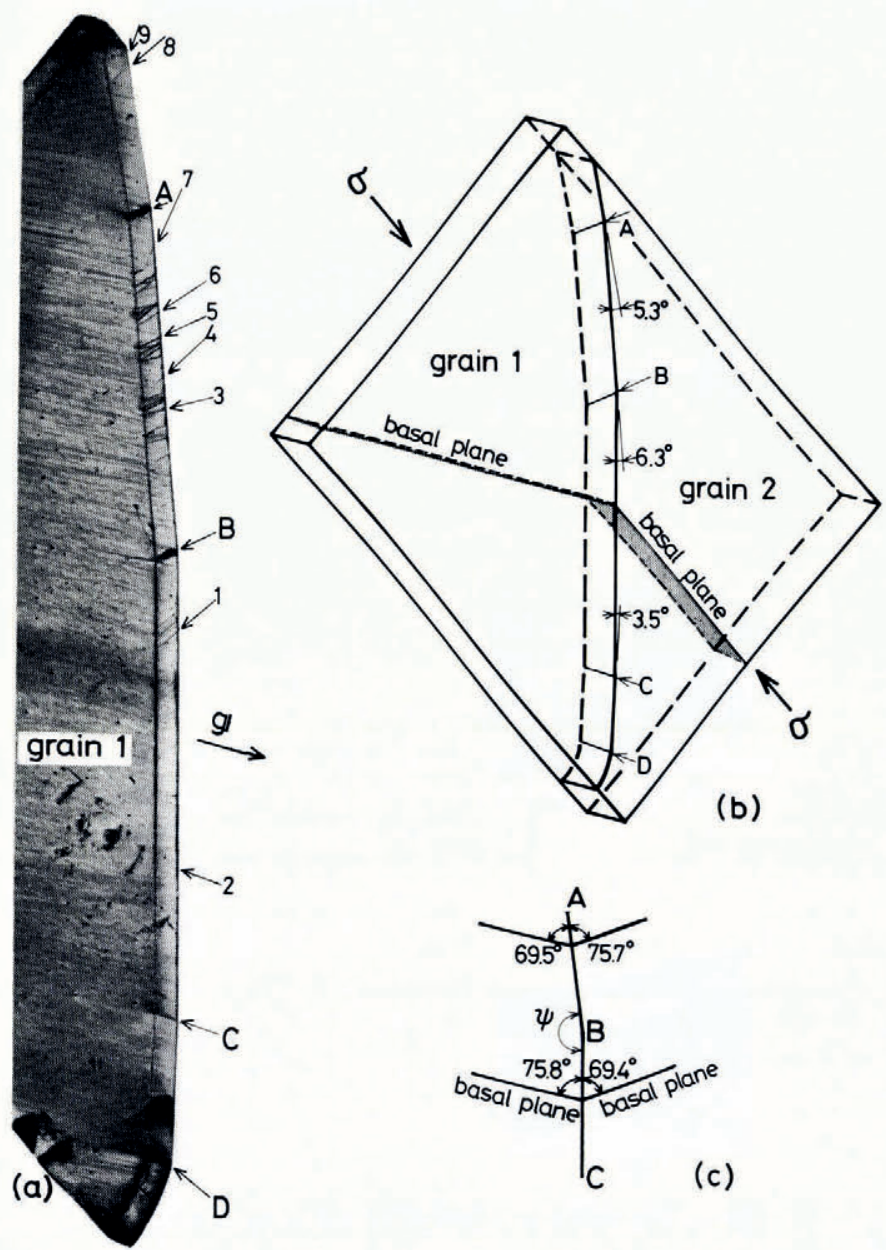

Fig. 2. Line defects on a bent $[\mathrm{I} O \overline{\mathrm{I}} \mathrm{O} \mathrm{O}] / 34^{\circ}$ tilt boundary.

(a) A topograph taken with ( $\mathrm{IO} \overline{\mathrm{I} O} \mathrm{O})$ diffracting plane just after a light deformation, compressive stress $\mathrm{\sigma} \approx 2.0 \times 1 \mathrm{O}^{5} \mathrm{~Pa}$ $\left(2.1 \mathrm{~kg} / \mathrm{cm}^{2}\right)$ was applied as shown on $(b)$ for $I O \mathrm{~s}$. Shear stress in the regions of $A B$ and $B C$ was approximately $I \times 1 O^{5} P a$ $\left(\mathrm{I} \mathrm{kg} / \mathrm{cm}^{2}\right)$.

(b) Schematic illustration of the specimen.

(c) Misorientations of the boundary planes $A B$ and $B C$ with respects to basal planes of both grains. 
to be [IOĪO] for both grains, are parallel to each other to within about $\mathrm{I}^{\circ}$. Since $\omega$ is approximately on the boundary plane ABCD, the intersections of the boundary plane with the basal planes of both grains were nearly parallel to $\omega$. The direction of a line defect, as described above, will be expressed in terms of the angle $\delta$ between $\omega$ and the line of the defect. $\delta$ for the line defects of $\mathrm{I}-\mathrm{I}^{\prime}$ and $2-2^{\prime}$ in Figure $\mathrm{I}$ are roughly $35^{\circ}$ and $\mathrm{O}^{\circ}$ respectively. The line defects $2-2^{\prime}$ in Figure I (c) did not appear on the topograph Figure $\mathrm{I}(\mathrm{b})$ which was taken with a [ Io $\overline{\mathrm{I}} \mathrm{O}$ ] g-vector. Since the line defects run parallel to the rotation axis $\omega$, or [ $\mathrm{ro} \overline{\mathrm{I}} \mathrm{O}]$, this is well understood from the extinction condition $\mathbf{g} \cdot \mathbf{U}=0$, if the displacement field vector $\mathbf{U}$ is assumed to be perpendicular to the line of the defect.

Lattice dislocation configurations inside the crystal did not change appreciably with light deformations as can be seen if Figure $\mathrm{I}(\mathrm{b})$ is compared with Figure $\mathrm{I}(\mathrm{a})$. However, boundary defects were generated by such a light deformation. Therefore, these grain-boundary defects are not the defects generated by the absorption of lattice dislocations. The fact that the same images appeared again after successive light deformations may imply that these defects are closely related to the grain-boundary structure itself and this presumption is confirmed by a set of observations shown in Figure 2.

Figure $2(\mathrm{a})$ is an X-ray topograph of a grain boundary of the same kind as before $\left(\theta=34^{\circ}\right)$ which was disposed in a specimen in the way shown in Figure 2 (b). The boundary bent several degrees at A, B, and C, and bent a good deal at D. Regions of AB, BC, CD, and the upper part above A were macroscopically flat, but the lower part below D was curved. Strong. images at bends A, B, C, and D and the other line images in Figure 2(a) appeared just after a light compressive deformation in the direction $\sigma$ on Figure $2(b)$. Two kinds of fine, parallel line images in the region $\mathrm{BC}$ correspond to those shown in Figure $\mathrm{I}(\mathrm{c})$. The angle $\delta$ between the line defects and $\omega=[\mathrm{I} O \overline{\mathrm{I}} \mathrm{O}]$ was roughly $35^{\circ}$ and $\mathrm{o}^{\circ}$ for grains $\mathrm{I}$ and 2 in Figure 2 respectively. Many strong images with different directions existed in the region $\mathrm{AB}$ as indicated by the numerals 3 to 7 . The crystallographic orientations of regions $\mathrm{AB}$ and $\mathrm{BC}$ were not

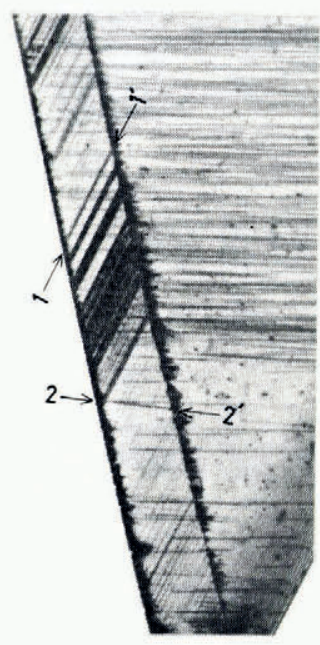

(a)

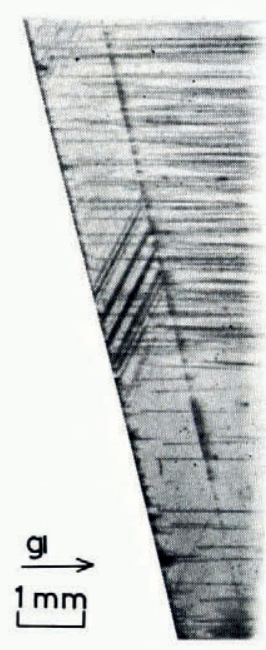

(b)

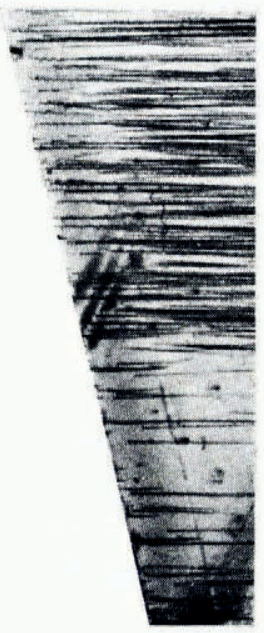

(c)

Fig. 3. Change of images of grain-boundary defects during ageing at $-20^{\circ} \mathrm{C}$. All topographs were taken with (I $\bar{I}$ oo ) diffracting
plane.

(a) A topograph taken just after a light deformation shear stress of $2.2 \times 10^{5} \mathrm{~Pa}\left(2.2 \mathrm{~kg} / \mathrm{cm}^{2}\right)$ was applied on the boundary

(b) A topograph taken after ageing for $4 \mathrm{~h}$.

(c) A topograph taken after ageing for $i d$. 
symmetrical, but made almost the same deviation from symmetry as is shown in Figure 2 (c). The line of the bend в is not parallel to the rotation axis $\omega$, although the line defect 2 is parallel to $\omega$. Even though the misorientation angle $\theta$ is approximately $35^{\circ}$ both for $\mathrm{AB}$ and $\mathrm{BC}$, such a small change in the orientation of the boundary plane introduced a large difference in the appearance of the boundary defects. Complex strain fields can be recognized in the lower region below $\mathrm{D}$, in which the boundary plane was considerably deviated from a symmetric disposition.

The images in Figures $\mathrm{I}(\mathrm{b})$ and (c) disappeared within a few hours of the end of the first deformation, but further deformations intensified those images and they then took a few days
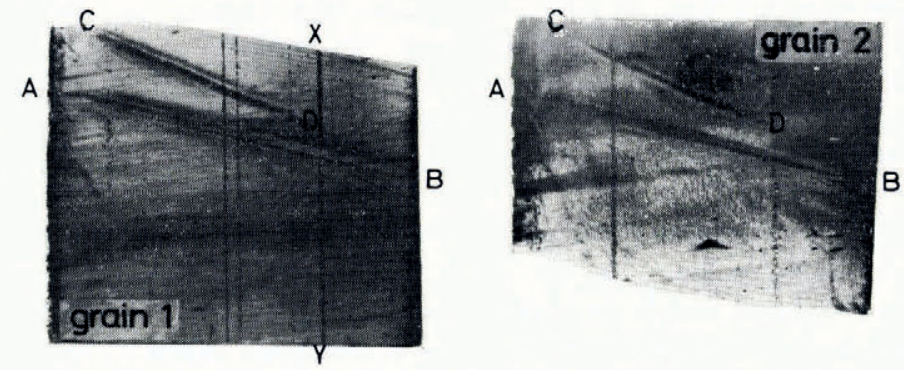

(a)
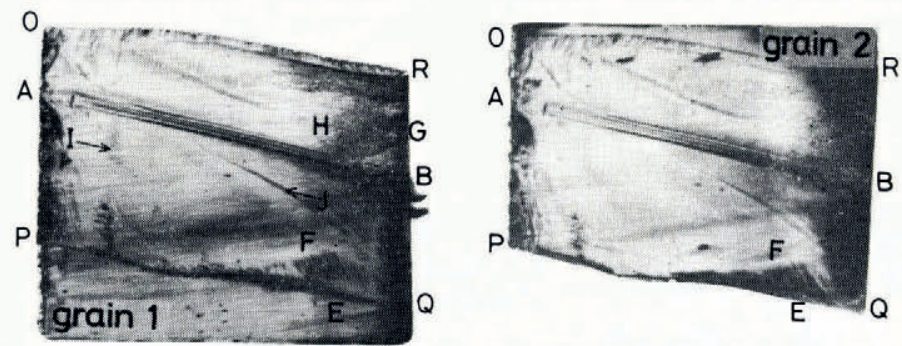

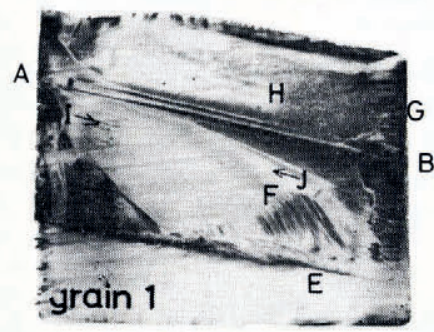

(c)

(b)

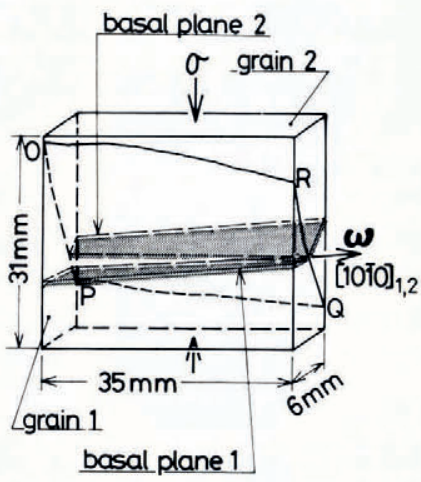

(d)

Fig. 4. Defects on the $[\mathrm{IO} \overline{\mathrm{I}} \mathrm{O}] / 47^{\circ}$ tilt grain boundary. All topographs were taken with (rō̄o) diffracting planes.

(a) Topographs before deformation.

(b) Topographs after the first deformation, shear stress of $5.4 \times 10^{4} \mathrm{~Pa}\left(0.55 \mathrm{~kg} / \mathrm{cm}^{2}\right)$ was applied on the boundary for $\mathrm{I}$ h.

(c) A topograph after the second deformation.

(d) A schematic illustration of the specimen. Rotation axis $\omega$ was not on the boundary plane exactly but its deviation was small. 
to disappear by ageing processes (Fig. I (d)). A typical disappearance of line defects at the boundary is shown in Figure 3. Weak images such as $I-I^{\prime}$ and $2-2^{\prime}$ in Figure 3 (a) completely disappeared in four hours and the strong ones gradually broadened (Fig. 3(b)) and became fainter after a day (Fig. 3(c)). After ageing for a few days, no boundary defects were recognized in the region BC in Figure 2, but the defects such as 3, 5, and 6 in the region AB were still visible and complex strain fields existed in the lower part below D.

Lattice dislocations on the basal plane seem to be generated from points where grainboundary defects meet the specimen surface as can be seen in Figure 3 (a). Therefore, lines of intersection of the boundary and the specimen surface would appear to be the most favourable sources for lattice dislocations during deformation.

\section{2. Specimen with $\theta=47^{\circ}$}

The dislocation density in the $47^{\circ}$ specimen was high (Fig. 4), so that faint images could not have been distinguished even if they had existed at the boundary. All of the topographs in Figure 4 were taken with (Iōo) diffracting planes in both grains $\mathrm{I}$ and 2.

Figure 4 (a) shows topographs taken just after the specimen was prepared. The images XY were generated by plane-blade scratches on the surface and they disappeared during ageing as shown in Figure 4 (b). The boundary plane was bent at AB and, less severely, at $\mathrm{CD}$. The images $\mathrm{AB}$ and $\mathrm{CD}$ were similar to those occurring along bends of the boundary as shown in Figure 2. Most characteristic defects begin at intersections of the boundary with the specimen surface and extend further into the interior along the boundary plane as deformation increases (e.g. EF and $\mathrm{GH})$. $\delta$ for EF was approximately $65^{\circ}$. These images disappeared in a few days during ageing at $-20^{\circ} \mathrm{C}$ as with the $\theta=34^{\circ}$ specimens. The angle $\delta$ between the rotation axis $\omega$ and those parallel line images which are just visible along IJ in Figures 4 (b) and (c) were roughly $20^{\circ}$. These line images are similar to the line defects $\mathrm{I}-\mathrm{I}^{\prime}$ in Figure $\mathrm{I}$, they are straight and inclined to the rotation axis with angle $\delta$. However, other images were very different from those obtained with the specimens with $\theta=34^{\circ}$.

\section{Discussion}

The fine, parallel line defects observed on the grain boundary of a $34^{\circ}$ specimen indicate that the grain boundary has an ordered structure. Coincidence site lattice (CSL) construction is useful in an examination of the periodicity of grain boundaries (see, for example, Brandon and others, 1964). A CSL is constructed from the coincident sites of two crystal lattices set at arbitrary misorientations. Although in general, the unit cell of a CSL is larger than that of the original grains, it becomes comparatively small when the disposition of the two grains satisfies certain special misorientation relationships. It is difficult to consider the CSL for the ice structure, so, for an approximation, we consider the simple hexagonal lattice with $c / a=\sqrt{ } 8 / 3$. Figure $5(\mathrm{a})$ shows the unit cell of the CSL formed for a $34.05^{\circ}$ rotation around the $[\mathrm{IO} \overline{\mathrm{I} O}]$ axis. Since 35 lattice points of each grain (open and closed dots) are included in a layer OPQR of the unit cell as shown in Figure 5(a), the reciprocal density $\Sigma$ of CSL points is 35. The same atomic arrangement is made on an adjacent layer shifted 1.7 $a$ to the direction [i 216$]$. A three-dimensional unit cell of the CSL is shown in Figure $5(\mathrm{~b})$. The value of $\Sigma$ in this CSL is not small, but the density of CSL points in the plane opts $\left(\overline{\mathrm{I}}_{2} \overline{\mathrm{I}} \mathrm{I}\right)$ is very high. Therefore, it is expected that the boundary has an ordered structure if the boundary plane lies on, or nearly parallel to, the $(\overline{\mathrm{I}} 2 \overline{\mathrm{I}} \mathrm{I})$ plane in a bicrystal with this misorientation.

The CSL theory predicts two kinds of line defects: structural grain-boundary dislocations, which compensate for deviations from exact CSL misorientation, and steps, which are generated by breaking the boundary into low-energy facets when the average boundary plane does not lie parallel to a high-density CSL plane. Structural grain-boundary dislocations 


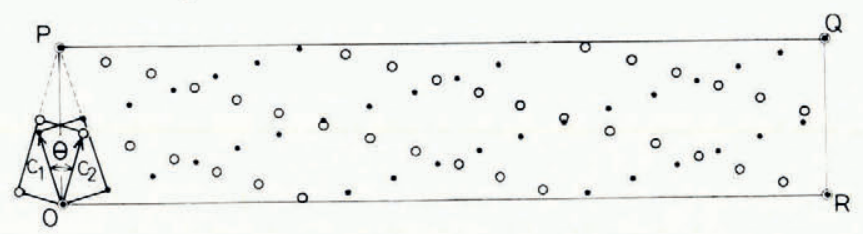

(a)

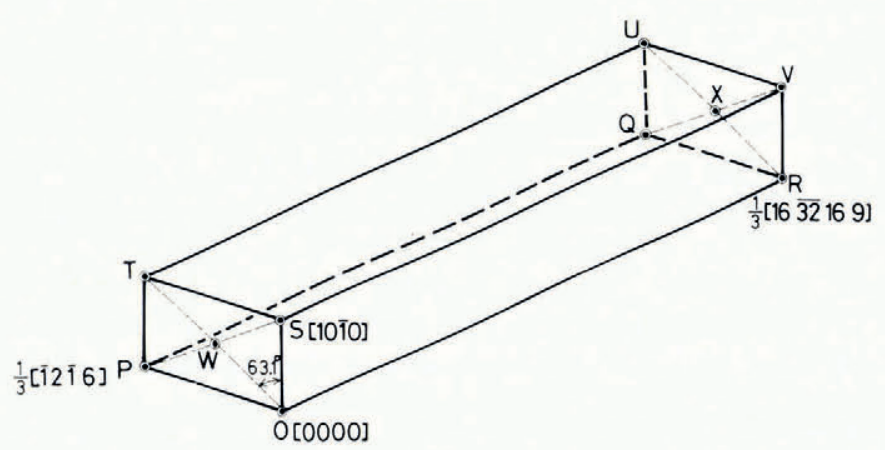

(b)

Fig. 5. Coincidence site lattice for the case of $\theta=34.05^{\circ}$.

(a) Arrangement of both lattice points on a layer perpendicular to the rotation axis $[\mathrm{IO} \overline{\mathrm{I}} \mathrm{O}]$ in a unit cell of CSL. Open dots are lattice points of grain 2 and closed dots are those of grain $I$.

(b) $A$ unit cell of the CSL, the rotation axis is $O S . O S \approx 1.7 a, O W \approx 1.9 a, O P \approx 3.4 a$, and $O R \approx I 6.7 a$, where a is the length of a-axis of ice. The plane OPTS coincides with $(\bar{I} 2 \bar{I} I)$ boundary plane.

have been observed in metals by electron microscopy (for example, Ishida and others, 1969; Balluffi and others, 1972) and it has been confirmed that they can exist on the boundary in an equilibrium state. Since the line defects observed on the grain boundary in ice disappear after annealing, they cannot be stable grain-boundary dislocations of this type.

Faceting of grain boundaries has also been observed in metals by many investigators, and it has been well explained by the CSL theory (Wagner and others, 1974). In a previous study which we have made into the boundary migration of ice bicrystals, ${ }^{*}$ macroscopic faceting of grain boundaries was observed, the facet planes being approximately parallel to the os, от, and Ps directions in Figure 5, all of which were close-packed directions of the appropriate CSL. Steps thus generated by faceting are probably strain-free in the equilibrium state. However, when the specimen is subjected to stress, and grains slide past each other on the boundary plane between the steps, new strain fields should be generated around the steps due to a concentration of plastic deformation there. Images of type $2-2^{\prime}$ in Figure $I(c)$ and of type 2 on the BC plane in Figure 2(a) appeared after deformation of the specimens and are well-understood to be steps around which strong strain fields were generated by the process described above. The fact that the displacement vector $\mathbf{U}$ of the $2-2^{\prime}$ line defects in Figure $I(c)$ is perpendicular to the line as described in Section 3.I supports this concept.

Clear, straight, parallel images of $\mathrm{I}-\mathrm{I}^{\prime}$ type in Figure $\mathrm{I}$ and of type $\mathrm{I}$ in Figure 2 may also be interpreted as a stepped structure of the grain boundary, although their direction $\left(\delta=35^{\circ}\right)$ is not parallel to any high-density row of CSL points on the $(\overline{\mathrm{I}} 2 \overline{\mathrm{I}} \mathrm{I})$ plane. The disappearance of the images after specimen annealing is similar to the behaviour of type $2-2^{\prime}$

* Paper by T. Hondoh and A. Higashi entitled "Anisotropic migration and faceting of large-angle grain boundaries in ice bicrystals", in preparation. 
images (Fig. 3) and indicates that the strain fields relaxed in about one day. Reappearance or these line images at the same sites on the boundary after further deformation also supports this idea.

It seems to be difficult to interpret the other, more complex images (from 3 to 7 on the plane $\mathrm{AB}$ in Figure $2(\mathrm{a})$ ) in terms of the CSL concept alone. The plane AB deviates from $\mathrm{BC}$ by $6.3^{\circ}$ as indicated in Figure $2(\mathrm{~b})$. However, on the microscopic scale, AB and BC make the angles with the basal planes of two grains in the bicrystal shown in Figure 2(c). Deviations from symmetry are the same for both $\mathrm{AB}$ and $\mathrm{BC}$, but defect structures on the boundary are quite different. Hartt and others (1974) observed similar curved grain boundaries in zinc and discussed a corrugated boundary structure which could explain the deviation of the misorientation from the exact CSL value. Further experimental studies are needed before such an idea can be applied to ice.

Complex strain fields are observed on the boundary as shown in Figure 4 and, as stated in Section 3.2 for the case of $\theta=47^{\circ}$, the angle deviates appreciably from an exact CSL misorientation relation (Higashi, 1978). These are more difficult to explain quantitatively. However, since the defects designated EF on Figure 4 extended during deformation and reappeared during repeated deformations even after they had disappeared during ageing, it can be said that the grain boundary of such a disordered structure has different types of structure and that these change regularly with straining along the boundary.

\section{REFERENGES}

Balluffi, R. W., and others. 1972. Electron microscope studies of grain boundary dislocation behavior, [by] R. W. Balluffi, Y. Komem and T. Schober. Surface Science, Vol. 31, p. 68-103.

Bishop, G. H., and others. 1971. Grain boundary faceting of $\langle$ IoIo $\rangle$ tilt boundaries in zinc, [by] G. H. Bishop, W. H. Hartt and G. A. Bruggeman. Acta Metallurgica, Vol. 19, No. 1, p. 37-47.

Brandon, D. G., and others. 1964 . A field ion microscope study of atomic configuration at grain boundaries, [by] D. G. Brandon, B. Ralph, S. Ranganathan and M. S. Wald. Acta Metallurgica, Vol. I2, No. 7, p. 81 3-21.

Hartt, W. H., and others. 1974. Grain boundary faceting of $\langle$ io io $\rangle$ tilt boundaries in zinc. II, [by] W. H. Hartt, G. H. Bishop and G. A. Bruggeman. Acta Metallurgica, Vol. 22, No. 8, p. $971-83$.

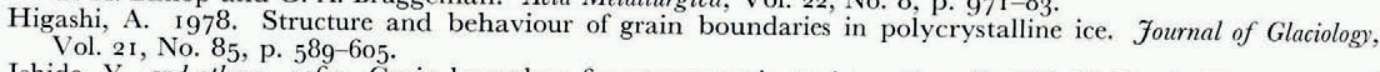

Ishida, Y., and others. I 969 . Grain-boundary fine structure in an iron alloy, [by] Y. Ishida, I. Hasegawa and F. Nagata. Journal of Applied Physics, Vol. 40, No. 5, p. 2 I $82-86$.

Loberg, B., and Norden, H. 1976. High resolution microscopy of grain boundary structure. (In Chadwick, G. A., and Smith, D. A., ed. Grain boundary structure and properties. London, Academic Press, p. I-43.)

Wagner, W. R., and others. 1974. Faceting of high-angle grain boundaries in the coincidence lattice, by W. R. Wagner, T. Y. Yan and R. W. Balluffi. Philosophical Magazine, Eighth Ser., Vol. 29, No. 4, p. 895-904.

\section{DISCUSSION}

W. B. KамB: What is the evidence on the basis of which you interpret the line defects seen in your grain boundaries as steps in the boundary surface? Why are the steps so straight and parallel, and yet not uniformly spaced?

T. HondoH: The fact that the line-defect images appeared only after the deformation and reappeared at some sites after successive light deformation implies that some line structures exist on the boundary to generate the strain fields around them after the deformation. Possible structures are microscopic stepped structures or corrugated structures generated by decomposing of a macroscope boundary plane to low-energy facets. We do not have any sufficient explanations about the directions of defect lines and spacing of them. 
D. R. Homer: Yesterday, I presented (Homer and Glen, i978, p. 436) some observations we have made of the deformation of bicrystals in which we suppress macroscopic grain-boundary sliding (we can, of course, say nothing about microscopic sliding). One of our observations was that cracks appear close to the grain boundary when specimens are deformed through a strain of perhaps 0.2. This is in some ways similar to your observations here. An explanation of such cracks can follow directly from your mechanism of grain-boundary steps. If the grains separate in the opposite sense to that in your diagram then a void, and possibly a crack, can form.

HondoH: Thank you for your comments. I have observed the macroscopic displacement along the boundary accompanied with grain-boundary migration during long-period shear deformation. I think this implies that migration of microscopic steps brings the macroscopic grain-boundary migration and the displacement along boundary.

\section{REFERENGE}

Homer, D. R., and Glen, J. W. 1978. The creep activation energies of ice. Fournal of Glaciology, Vol. 21, No. 85, p. 429-44. 